\title{
Phenomenon of a Teacher Within a Historical Context
}

\author{
Elena Ilaltdinova, Irina Lebedeva, Svetlana Frolova, Ramilya Arifulina, Tatyana Belyaeva \\ ${ }^{1}$ Minin Nizhniy Novgorod State Pedagogical University (Minin University), 603950, Ulyanova, 1, Nizhniy Novgorod, Russia
}

\begin{abstract}
The study concerns the phenomenon of a "professional teacher", its social status, personal qualities and competences within the historical context. The authors apply the integration of philosophical, psychological, historical-pedagogical and pedagogical knowledge as such to understand the modern model of a teacher. The historical context as a complex of social conditions of pedagogical insights, concepts and assumptions of an ideal teacher and its professional training formed methodological fundamentals of the study dealing with the image of a teacher of the past, present and future. To define the mission of a teacher within the society and its professional characteristics the study analyzes beliefs, activities and works of educators, scientists, classic teachers and modern representatives of pedagogical science and educational practice. Defining the phenomenon of a "teacher", the authors consider it through the unique nature of professional activity, personal qualities, compliance to public expectations and demands.
\end{abstract}

The social role of a teacher is unexceptionally considered one of the priority fields in various sciences. The study of an image of an effective teacher, its public mission and social responsibility gains special attention during the modern period of educational development, which is characterized by substantial modernization and reforms. The importance of studying a phenomenon of a teacher-educator in society is highlighted by many Russian scientists in the field of education (M.A. Lukatsky, I.D. Lelchitsky, E.Yu. Yesenina, V.A. Rybin, etc.) and western researchers (K.A. Parker, K. Bikmor, S. Rivkin, E. Hanushek, J. Lockwood, etc.). They all share common views on the transformation of social positions of modern teaching due to serious conditions and problems of social life in general, parenting relations, young people, and school life. There is a need for multidimensional analysis related to the study of social conditions and features of the present era to understand an ideal image of a teacher continuously trying to form any progress-oriented society. Moreover, every region of the world is characterized by its authentic educational system, key link in which is the image of the educator that embraces national specificity [1].

Global trends towards reorganization of education are, first of all, bound to a complex social context demanding sophisticaled approach of a teacher to the improvement of its professional competences. Thus, the devaluation of a family role and family values, increase in destructive communities, confessional dissociation, appearance of radical youth movements and groups, violence in society, etc. emphasize the need to review requirements to both professional and personal qualities of a teacher. At the same time, as some researchers note, modern society is characterized by certain elimination of a pedagogical value, the pedagogical profession as such, loss of a teacher's cult, degradation of spiritual teacherstudent relations. Scientists tend to associate this with the prevalence of technological models forming the educational processes, where the role of a teacher is shifted from a mentor to a "technologist" instructing a student to perform the necessary actions or operations. The pedagogical theory and educational practice more often uses such terms as a coach, a supervisor, a moderator, a facilitator, a tutor, etc., which illustrates specific functions of a teacher in modern society $[2,3]$. At the same time, some authors exclude the polysemy of their interpretation and equate their meaning to a traditional notion of a "teacher" [4].

The above contradictions foster the need of modern understanding of the concept "educator" and increase scientific and practical interest to the pedagogical profession in general.

The study implicitly values views, efforts and works of philosophers, educators, scientists, classic teachers, which made it possible to define historical fundamentals of the origin and development of the notion of "educator". Hereof it follows that only the combination of philosophical, psychological, historical-pedagogical and pedagogical knowledge as such may contribute to the understanding of the integrated model of the educator. It should be emphasized that it is critical to understand pedagogical ideas and their implementation through a wide historical context - obligatory study of pedagogical beliefs and concepts within culture and society, where they appeared, developed, were broadcasted, interacted, were changed or terminated [5, $6]$.

In fact, during various historic periods the role and value of an educator in society triggered the minds of outstanding people, even those whose activity was far from pedagogical: philosophers, teachers, statesmen, 
politicians, writers. They tried to understand and define characteristics of the educator without which, according to them, it was impossible to achieve success in development and education of a personality, and the importance of their concerns has always defined the respect towards a pedagogical profession. Despite universal figurative characteristics of the educator (dedicated, love for children, ethical, disinterested, honest, etc.), any era is posing new requirements to its personal qualities and professional abilities.

The image of the professional educator as an ideal model of a person in general and the holder of spiritual knowledge which he/she shares with students has always been key in the society. Therefore, the educator was traditionally characterized within the personal and professional context. The analysis of modern approaches to the study of the educators' role in human civilization allows presenting its phenomenological characteristics in a wider perspective: through unique professional activity; through personal qualities; through compliance to public expectations; through public demands.

The characteristic of the educator through unique professional activity is the most widespread approach to the study of the phenomenon of an "educator". In the minds and beliefs of the representatives of this profession there is deep and elevated understanding: "the position of the educator is so superior compared to any other on earth" (Ya.A. Komensky, 17th century) [7].

Such statements underline unique features of an educator's profession, which implies continuous mutual enrichment of the educator and students through the development of their motives to personal and educational communication, establishment of special relations in pursuing new knowledge, mindset and experience, mutual "penetration" into each other's spiritual world.

It was typical for researchers of the 20th century to consider the activity of the educator through professional functions, and the educator's activity was described through their high-quality performance, i.e. through the system of corresponding abilities. Thus, N.V. Kuzmina identifies gnostic, design, constructive, organizing, and communicative functions of pedagogical activity; V.I. Ginetsinsky highlights presentation, inceptive, correcting and diagnosing functions; A.I. Scherbakov emphasizes constructive, organizing, and research functions. Within the given context one can't fail to agree with E.V. Piskunova that the described functions, being not only interrelated but also substantially intersecting, do not fully reflect the metaactivity nature of pedagogical activity, which by nature cannot be linear [8]. Therefore, there is a need for additional criteria to characterize the effective educator.

The characteristic of the educator through personal qualities is an approach to the description of an ideal image of the educator through "cross-cutting" personal qualities. This approach penetrates through the entire history of human understanding of a phenomenon of the educator as ideal, role model, and perfect human being and an example to follow. The use of the concept "educator's ideal" significantly expands frameworks of historical and pedagogical consideration of the matter. It allows not only becoming acquainted more deeply with key aspects of the history of a pedagogical thought, but also with a vital issue of the educator's phenomenon in the context of culture and education. By conveying the experience of organizing the sociocultural life from one generation to another, the educator promotes personal and professional growth of students. Such attitude towards the educator can be traced in beliefs of people from different countries and eras irrespective of their sphere of professional interests: writers, philosophers, politicians, public figures, publicists. Intrinsic features of the educator's image were defined by people belonging to this profession and who are historically called outstanding: "The personality of the educator means everything in education" (K.D. Ushinsky).

It is beyond controversy that the educator's personality cannot only be described through emotional characteristics thus placing it upon a professional "pedestal". Commitment to a profession and readiness to fully dedicate yourself define the internal determination of the educator, understanding of his/her calling and duty. The requirements to personal qualities of the educator were changing throughout centuries: differentiated, integrated, mastered, which can be easily explained by historical and cultural transformations of a human civilization. Moreover, within one historical period different views and approaches to the educator and his characteristics can intertwine. Gradually, the mass public consciousness formed the stereotype of the ideal educator with the democratic communication style motivating students for active creative growth; the creator inspiring with his entire personality and expertise. Due to this fact the main mission of the educator came through centuries, i.e. education (outreach) not only to students, but also to everyone who needs it. With this in mind it should be noted that the comparative analysis of professional and personal qualities of the teacher in different regions of the world reveals that the national image of the teacher is affected by the geography, national and cultural features, customs and traditions of a region. Yet, along with national specificity, it is obvious that great teachers display such qualities that are characteristic of every "ideal image" outside the national or geographic context [9].

As for the Russian national ideal of a teacher it always included such top qualities as sacrifice, unselfishness, self-denial and missionary work. In the conditions of the market relations in Russia such category as "educational service" appeared that as any others has its price [1].

The characteristic of the educator through compliance to public expectations, i.e. sociocultural conditionality of professional and pedagogical activity. Such direction of the study allows considering the educator's phenomenon as the central figure of public transformations since the results of professional activity strongly depend on his personal efforts, social position, and value-based objectives. The most accurate and direct understanding is the educator's impact on society through the influence on a state policy in the field of education, attraction of social forces to the educational process [10]. 
This may be justified by the activity of the Russian companions of the 19th century (N.I. Pirogov, N.A. Dobrolyubov, D.I. Pisarev, I.N. Ulyanov) and the movement of innovative educators of Russia promoting the society to accept the necessary transformations in education in general and its separate components, as well as contributing to the formation of a new sociocultural type of personality.

With this approach the educator is perceived as an active and independent professional leader aimed to produce essential educational and social effects. This concept is undoubtedly based on the idea of teaching as a practical profession, according to which any theorize concerning the educator's training shall find immediate acknowledgement in real life. The society perceives the educator as an example of fidelity to a professional duty, goodness, nobility, self-development, and selfimprovement. In this context the notion of a "pedagogical community", which includes the educator in the structure of collective professional interaction and where the expert in the field of education becomes a member of steady social cohort dividing its specifics and interests, is becoming ever more critical. A more complex approach to the understanding of the educator as a central figure of public transformations is the understanding of his high role as a social reformer. His activities foster the fulfillment of a social reconstructionism function, i.e. transformation and improvement of a society is ensured through pedagogical methods (J. Dewey, A.S. Makarenko, M. Montessori, R. Steiner and their followers).

The characteristic of the educator through public demands. This perspective to consider the educator's image characterizes the educational process as social and humanitarian practice focusing on personal understanding of the world by a student thus ensuring his self-realization and formation of identity, self-education, design of individual educational trajectory, smooth and adaptive management (N.L. Selivanova) of his development.

Thus, E.V. Piskunova states that it is "time to implement the subjective approach in education, ensure unconditional right of each child to actively choose and independently design the school life. School shall adopt and prioritize three new "subjects": how to study effectively, how to make decisions, how to become an independently acting manager of the future» [8]. In this prospect it is necessary to add the ability to assume responsibility for decisions and actions.

It remains without saying that such understanding of the educator's role in the development of students was not at once adopted by the society. It took years of thorough search, multidimensional experience, experiments, fight of theories and ideas. Nevertheless, the image of the ideal educator, with whom students always find it interesting to talk on friendly terms, with democratic communication style able to make a productive team with students based on spiritual communication, was gradually and successfully formed in mass public consciousness. It is the "teacher by calling always surrounded with children that feel calm and free close to him. The work of such teacher is aimed to make students happy and merry, he does not imitate others, and acts as a creator inspiring and provoking the interest among children. The teacher by calling centers entirely around children, and children around him" (Lubenets T., National teachers . Russian school. 1912. - No. 3. - pp. 31). Such style of communication between the teacher and the children was typical for the representatives of "domestic" pedagogics (I.G. Pestalozzi, L. Tolstoy, O. Rachinsky); for anthropological movement (K. Ushinsky), which subsequently gained further development in personoriented approach of humane pedagogics (M. Montessori, G. Gmayner, Sh. Amonashvili, I. Goncharov, etc.). Modern pedagogics applies the term "progressivism", which is treated as the field of education philosophy based on priority of interests and needs of a child. Its representatives (J.-J. Rousseau, O. Dekroly, J. Dewey, etc.) believed that the main objective of education is to create conditions for development of children through the creation of free developing environment able to discover the internal potential of the growing personality.

Thus, the analysis of historical characteristics of an image of the ideal teacher confirmed the integrative character and the need to consider social and cultural features. The activity and heritage of outstanding representatives of the pedagogical science and educational practice of different eras allows tracing the continuity of ideas and requirements to the teacher, as well as differences in national educational traditions. At the same time, major and demanding challenges of modern society imply continuous improvement of professional level of modern teaching through mastering of cross-cultural competences. Due to this the description of an image of the modern teacher requires multidimensional analysis based on dialectic interrelation of its characteristics: through unique features of a profession, personal qualities, public expectations and student needs.

\section{References}

1. E. Y. Ilaltdinova, S. V. Frolova, I.V. Lebedeva, Advances in Intelligent Systems and Computing 677, 44-52 (2018)

2. I.V. Lebedeva, S.I.Aksenov, Modern problems of science and education 6 (2014)

3. E.I.Sokolova, Continuous education: 21 st century 4, (2013)

4. A.V.Utkin, Bulletin of Russian State Pedagogical University named after A.I. Herzen, 94 (2009)

5. M.V. Boguslavsky, Methodology, contents and technologies of education (historical and pedagogical context). Monograph, (2007)

6. G.B. Kornetov, Pedagogical paradigms of basic models of education. (Publishing house of the University of the Russian Academy of Education, 2001) 
7. V.M. Klarin, A.N. Dzhurinsky, Ya.A .Komensky, J. Lokk, Zh. Zh. Russo, I.G. Pestalozzi, Pedagogical legacy, (1989)

8. E.V. Piskunova, Bulletin of Russian State Pedagogical University named after A.I. Herzen 9, 71 (2009)

9. S.I. Aksenov, R.U. Arifulina., T.K. Belyaeva, E.Y. Ilaltdinova., I.V. Lebedeva, Journal of Entrepreneurship Education 3, 20 (2017)

10. V.P.Zasypkin, Bulletin of Russian State Pedagogical University named after A.I. Herzen 42(9) (2007) 